\title{
Clinical ethics support services in the UK: an investigation of the current provision of ethics support to health professionals in the UK
}

Anne Slowther, Chris Bunch, Brian Woolnough and Tony Hope University of Oxford, Oxford

\begin{abstract}
Objective-To identify and describe the current state of clinical ethics support services in the UK. Design- $A$ series of questionnaire surveys of key individuals in National Health Service (NHS) trusts, health authorities, health boards, local research ethics committees and health professional organisations. Interviews with chairmen/women of clinical ethics committees identified in the surveys.

Setting - The UK National Health Service.

Results-Responses to the questionnaires were received from all but one NHS trust and all but one health authority/board. A variety of models of clinical ethics support were identified including twenty formal clinical ethics committees (CECs). A further twenty NHS trusts expressed an intention to establish a CEC within the next twelve months. Most CECs in the UK have been in existence less than five years and are still defining their role. The chairmen identified education of committee members and contact with other ethics committees as important requirements for committee development. Problems were identified around lack of support for the committee and with raising the profile of the committee within the institution. There has been little evaluation of clinical ethics support services either in the UK or in other countries with longer established services. What evaluation has occurred has focused on process rather than outcome measures.

Conclusions-Clinical ethics support services are developing in the UK. A number of issues have been identified that need to be addressed if such support services are to develop effectively.

(Fournal of Medical Ethics 2001;27 supp1 I:i2-i8)
\end{abstract}

Keywords: Clinical ethics committee; health professionals; ethics support; health care ethics committees

\section{Introduction}

In recent years, consideration of ethical issues has become an important and frequent part of discussions around health care within the UK, both at the level of the individual patient and at a population level. A number of factors have contributed to this increase in the discussion of ethics. The mapping of the human genome, techniques for assisted reproduction and improved life-support mechanisms offer new opportunities for treatment but also raise ethical concerns. The development of effective but expensive treatments, an increase in chronic disease and an ageing population raise new questions of priority setting. The recent inquiries into paediatric cardiac surgery at Bristol, and the removal of the organs of dead children at postmortem examination without parental consent at Alder Hey, have focused as much on the ethical integrity of clinicians and health care institutions as they have on clinical competence.

Within this framework of raised ethical awareness and demand for public accountability, how can individual health professionals and health care institutions ensure high ethical standards in all aspects of patient care? Some support for health professionals on ethical issues in clinical care already exists in the UK in the form of guidelines from national bodies and professional organisations. ${ }^{12}$ However, local support services may be needed to provide support that is responsive and relevant to local circumstances. There is some evidence to suggest that such support services would be welcomed by clinicians. ${ }^{3}$

Clinical ethics committees (CECs), also called hospital or institutional ethics committees (HECs), have been a feature of health care in North America since $1971,{ }^{4}$ and their number increased dramatically in the 1980 s. $^{5}$ Clinical ethics committees have also developed in Europe and Australia although they are less widespread than in North America. ${ }^{6-9}$ Ethics consultation services provided by individual ethics consultants or teams have also developed, sometimes in association with a CEC and sometimes separately. ${ }^{10} 11$ The methodology for the assessment of clinical ethics support services is poorly developed. A few studies have tackled this issue, primarily focusing on process rather than outcome measures. ${ }^{12}$ In the UK research ethics committees are well established but there are few data on CECs. There have been published reports on five different CECs, ${ }^{13-15}$ and anecdotal evidence suggested that there were other CECs developing within the UK as well as other methods of clinical ethics support. The aims of the study reported in this paper were:

1. To identify all ethics support services relating to clinical practice currently provided for health professionals working in the UK. 
2. To investigate the perceived need for such a service among senior managers and clinicians within the health service.

3. To describe in detail the structure and function of established CECs in the UK.

\section{Method}

The investigation comprised two main types of study:

1. A number of closely related questionnaire surveys.

2. Structured interviews with the chairmen of CECs identified in the questionnaire surveys.

\section{OUESTIONNAIRE SURVEYS}

Several brief questionnaire surveys of the following groups were carried out:

- chief executives, chairmen, medical directors, directors of nursing and directors of operations (ambulance trusts) in all NHS trusts in the UK:

- chief executives, chairmen, directors of public health and, where applicable, directors of primary care services in health authorities and health boards in the UK;

- chairmen of all local research ethics committees (LRECs) and,

- senior officers in identified professional organisations.

In addition, written requests for information were sent to identified individuals in university departments of medical ethics.

\section{Sampling}

All NHS trusts, health authorities and health boards, and professional organisations were identified using the medical directory, and the names of individual postholders were recorded. Chairmen of LRECs were identified using the national database of LRECs held at King's College, London.

All subjects were sent a brief questionnaire accompanied by a letter explaining the nature of the study and the fact that the study focus was on clinical ethics and excluded information about research ethics. Two postal reminders were sent. For trusts and health authorities where no postholders replied a further telephone request was made to the medical director or director of public health. Between the initial questionnaire mailing and the first reminder there was a significant change in NHS trusts, with some trusts merging and new trusts forming. Therefore, following the first reminder a confirmatory check was made to ensure the database included all current trusts using the NHSE website (England), the Welsh Office (Wales), the Northern Ireland health and personal social services website, and the Scottish health organisations website. Trusts that no longer existed were removed from the database, new trusts were added and questionnaires were sent to the appropriate personnel. The final database included all NHS trusts active on the first of April 2000.

The questionnaires developed for each group were slightly different to reflect their different health care roles but each questionnaire was designed to answer two main questions:

a) Did the trust/health authority/research ethics committee/professional organisation provide support on ethical issues relating to clinical practice as opposed to research?

b) Did the person completing the questionnaire perceive a need for clinical ethics support for health professionals in his or her organisation?

\section{INTERVIEW STUDY}

Interviews were conducted with the chairmen of all clinical ethics committees in NHS trusts identified in the questionnaire survey. The interviews lasted between 30 and 60 minutes and were taperecorded. Four interviews were not recorded for technical reasons but contemporaneous notes were taken. A topic guide was developed covering the following areas:

1. The structure of the committee (membership, terms of reference, experience/expertise of members, training).

2. The functions of the committee (case consultation, policy development, education, other functions).

3. The development of the committee (reason for development, profile of the committee within the trust, achievements, problems).

4. The views of the chairmen on the future development of the committee.

The interview transcripts were analysed to obtain factual data, and to identify themes relating to the specific topic areas.

A full description of the methods is given in the study report. ${ }^{16}$

\section{Results}

QUESTIONNAIRE SURVEYS

Response rates

A total of 2,363 questionnaires were sent. Responses were received from:

- $99.8 \%(455 / 456)$ of all NHS trusts $(71.3 \%$ (1273/1784) of individual postholders);

- $99.2 \%(123 / 124)$ of all health authorities/health boards $(78.8 \%(238 / 302)$ of individual postholders);

- $90.0 \%(208 / 231)$ of chairmen of LRECs;

- $95.0 \%(20 / 21)$ of those national professional organisations surveyed.

Level of ethics support currently provided

1. NHS trusts: Of those NHS trusts active on April 1st 2000, 18\% (84/456) have already identified some formal method of addressing ethical issues arising from clinical practice within the trust. These vary from specific services dedicated to the provision of clinical ethics support to the incorporation of ethics into existing trust structures such as a clinical governance committee or professional advisory committee. (See figure 1.)

2. Health authorities and health boards: A resource allocation or priority setting committee 
i4 Clinical ethics support services in the UK: an investigation of the current provision of ethics support to health professionals in the UK

Figure 1: number of NHS trusts reporting different models of formal clinical ethics support. Some trusts have more than one model



that addresses ethical issues was reported in $14 \%(18 / 124)$ of health authorities and health boards.

3. Local research ethics committees (LRECs): Some health professionals see LRECs as a source of advice on ethical issues relating to clinical practice. Forty-two per cent $(88 / 208)$ of responders to the LREC questionnaire stated that their committee had been asked for advice on clinical ethical issues and $25 \%(52 / 208)$ stated that the committee had provided such advice.

4. Professional organisations: Of the responders to the professional organisation questionnaire, $57 \%(23 / 40)$ stated that the organisation had some form of clinical ethics support for members. (See table 1.)

5. University departments of medical ethics: Of the eighteen individuals in departments of medical ethics approached for this study responses were obtained from fifteen $(82 \%)$, and

Table 1 Type of formal support on ethical issues in clinical practice provided by professional organisations

\begin{tabular}{ll}
\hline Type of support & $\begin{array}{l}\text { Number of organisations with } \\
\text { such support }\end{array}$ \\
\hline Ethics committee & 15 \\
Written guidelines & 14 \\
Telephone advice & 11 \\
Education & 7 \\
Other & 7 \\
\hline
\end{tabular}

$60 \%(10 / 15)$ of those responders stated that they had been approached by clinicians for advice on ethical issues relating to patient care. Of those who had been approached, $50 \%$ received requests at least once a month and $50 \%$ received requests infrequently. Those individuals who received requests at least once a month were personally involved in a clinical ethics committee or an assisted conception ethics committee.

\section{Perceived need for clinical ethics support}

- Of those respondents to the trust questionnaire who answered the question on perceived need for a clinical ethics support service, 89\% (557/620) agreed or agreed strongly that the trust should have such a service. The respondents represented $80 \%$ of all trusts. A clinical ethics committee was favoured by $62 \%(365 / 587)$ of these responders, 26\% (152/587) favoured an ethicist and $12 \%$ suggested another model of service.

- Of the responders to the health authority questionnaire, $50 \%(120 / 238)$ felt that a clinical ethics support service would be useful in the health authority, and $84 \%$ (199/238) thought that the health authority had a role to play in providing support or advice to primary care groups/trusts on ethical issues relating to clinical practice and/or resource allocation. 
- Of the responders to the LREC questionnaire, $85 \%(177 / 208)$ thought that there was a need for ethics support on clinical issues within the NHS organisations that referred research proposals to the LREC.

- Of the responders to the professional organisation questionnaire, $57 \%(12 / 21)$ thought that the ethics support provided by their organisation to health professionals should be improved.

\section{General comments on clinical ethics support}

The questionnaires administered to the trusts and health authorities/boards provided space for general comments. Comments were made by $12 \%$ (208/1713) of trust respondents and 24\% (56/238) of health authority/board responders. The majority of comments indicated recognition of the need for a mechanism to raise awareness of ethical issues within the institution. One respondent wrote: "I feel very strongly that there are circumstances in practice, and our relationships with patients and their families, which could be handled better if we had access to individuals or processes which support ethically based decision making."

However, just under $20 \%$ of those commenting in the trust questionnaire expressed a clear opinion that any form of clinical ethics support was unnecessary within individual NHS trusts. They felt that ethical decisions were an intrinsic part of a clinician's work and support from senior colleagues was more appropriate than external mechanisms. One respondent wrote: "I am somewhat alarmed at the growth of quasi formal/regulatory committees and much prefer sensible informed decisions between colleagues."

Some health professionals within trusts, including those in favour of clinical ethics support, expressed concern about the feasibility of providing such support in general, and concern with doing this through clinical ethics committees in particular. These concerns included:

- the cost of setting up such a service;

- the need for a rapid response to requests for advice in urgent clinical situations;

- the establishment of yet another committee, increasing bureaucracy within the trust;

- that the clinical autonomy of health professionals would be compromised.

There were also positive suggestions on what form, other than an ethics committee, a clinical ethics support service should take. These included:

- small groups or individuals within the trust;

- an extension of current clinical supervision arrangements;

- regional committees covering more than one trust.

Table 3 Funding available for clinical ethics committees
Table 2 Membership of committees

\begin{tabular}{ll}
\hline Group & $\begin{array}{l}\text { Number of committees with } \\
\text { members of this group }\end{array}$ \\
\hline Consultant/Medical Director & 20 \\
Junior doctors & 3 \\
Nurse managers & 17 \\
Junior nurses & 1 \\
Other clinical professionals & 10 \\
Non-clinical manager & 10 \\
Chaplain & 11 \\
Lawyer & 4 \\
Ethicist/philosopher & 10 \\
Lay/patient representative & 15 \\
General practitioner & 6 \\
Trust Board member & 11 \\
\hline
\end{tabular}

\section{INTERVIEW STUDY}

Development of the committees: Only four $(20 \%)$ of the twenty clinical ethics committees had been established for more than five years. Most of the committees had been established because of concern by clinicians about difficult cases or issues they had encountered. Two committees developed from a trust research ethics committee (not from a LREC) when it became clear there was a need to consider ethical issues other than those arising from research within the trust. One committee was established on the initiative of the trust board and one on the initiative of the chief medical officer in the health authority

Committee membership: All committees were multidisciplinary but the mix of disciplines and the presence of lay members differed between committees. (See table 2.)

Some committees' terms of reference made allowance for other people to be co-opted on to the committee for discussion of specific issues. Seventy per cent $(14 / 20)$ of committees had a senior doctor as the chairman.

Funding: Fewer than half of the committees had access to funding. Sources of funding included the trust board, education and training budgets, specific grants and local research ethics committee funding. Some committees had funding for more than one purpose. (See table 3.)

Except where specific funding had been allocated, administrative support for the committee was usually provided by the chairman's secretary, and in at least one case the chairman wrote the minutes of committee meetings.

Functions of the committee: The terms of reference of the established CECs identify three main functions of the committees: support for individual clinicians; input into trust policy and guideline formation, and education of health professionals within the trust.

\begin{tabular}{lllll}
\hline Type of funding & $\begin{array}{l}\text { For education/ } \\
\text { training }\end{array}$ & For an ethicist & Administrative & $\begin{array}{l}\text { Total with } \\
\text { no funding }\end{array}$ \\
\hline Number of committees with access to funding & $5(25 \%)$ & $2(10 \%)$ & $4(20 \%)$ & $11(55 \%)$ \\
\hline
\end{tabular}

Some committees have funding for more than one purpose. 
i6 Clinical ethics support services in the UK: an investigation of the current provision of ethics support to health professionals in the UK

Table 4 Guidelines and policy issues reported as being addressed by clinical ethics committees

Do not resuscitate (DNR) guidelines

Consent policy

Advance directives

Rights and duties of relatives

Confidentiality

Consent to participate in undergraduate education

Withholding and withdrawing of treatment

Guidelines relating to HIV

Policy for dealing with the media

Commercial use of tissue

Consent for DNA testing

Total parenteral nutrition

Use of restraints

Elective ventilation

Possession of illicit drugs

Abuse of services by members of the public

The role of committees in guideline and policy development covered three main areas:

- consideration of both existing and developing hospital policies, and advice on the ethical issues arising from them;

- identification of areas of concern, where a policy or set of guidelines may be required and then input into their subsequent development;

- development of guidelines on specific ethical issues by the committee for consideration and ratification by the trust board.

A range of policies and guidelines have been considered by the currently established committees in the UK. (See table 4.)

Most committees used retrospective case discussion as a form of self-education for the committee members. Several of the chairmen commented that issues arising from individual cases often highlighted a need for the development of a policy or guidelines. Eight committees have engaged in discussion of active cases and provided advice and support in these cases. The frequency of requests for advice on active individual cases is low (usually less than two per year) although one committee in an acute trust had received thirteen requests over the two years that it had been functioning. Three acute trusts have an ethicist on the committee who also gives advice and support to individuals and care teams within the trust. These ethicists are attached to local university departments and are not funded by the trust. (See table 5.)

Table 5 Some issues raised in 'active' case consultations conducted by CEC

Confidentiality around HIV testing

Refusal of life-saving treatment

Refusal of spouse to give permission for life-saving treatment because of patient's previously stated views

Request from relatives not to divulge distressing information to a person with learning disability

Use of restraint to allow appropriate treatment

Relatives requesting information about patient

Conflict between medical team and parents over use of CPR in

severely disabled children

Withdrawal of treatment

Advance directives
Table 6 Models of educational initiatives by clinical ethics committee

\section{Grand rounds}

Seminars or workshops on specific issues

Educational document on consent

Inclusion of ethics in postgraduate seminar programme

Teaching of specific groups by individual member of committee

All committee chairmen highlighted the importance of education on ethical issues for all health professionals within the trust, and agreed that one role of the committee may be to initiate or facilitate such education. Education was seen as one way of raising the profile of both the committee and clinical ethics in general across the trust. However, few of the committees were actively involved in education in a regular or structured manner. There were various reasons for this, most commonly lack of resources (time and money) and a lack of confidence among ethics committee members in their ability to educate others when they were still learning. (See table 6.)

Evaluation: Only one clinical ethics committee had so far undertaken any formal evaluation of its process or function. Most committees produce an annual report describing the work of the committee.

\section{Issues arising from the interviews}

A number of issues were raised in the interviews.

1. The professional status of the committee chairman: It was generally felt that the chairman did not need to be a doctor and that the position could be held by another health professional or a lay person. However, there was a view that the chairman needed to be someone with authority and respect within the trust in order that the committee was perceived as important by employees of the trust. The support of the medical staff was seen as essential for the useful functioning of the committee and resistance from them as a potential barrier to the committee's effectiveness. Therefore, from a pragmatic viewpoint it was widely thought that a senior doctor as chairman is desirable in the early development of the committee.

2. Does the committee need an ethicist? The views of the chairmen on the need for an ethicist or philosopher on the committee were sought. Some thought that an ethicist, or someone with a qualification in ethics, was essential to the effective functioning of a clinical ethics committee. One chairman said: "I think that the idea of having a committee like this without appropriate expertise all round is absurd."

Others thought it was more important to have clear thinking, articulate people with an interest in ethics and an ability to place the issues in a practical context, rather than a designated expert with no practical experience. "I think many of the people with expertise in this area are theoreticians rather than practitioners."

One chairman expressed concern about bringing in someone from outside the trust who would not have practical experience of the trust. 
3. Training for committee members: All chairmen thought some training for committee members was desirable. The two main barriers to achieving this were lack of funding and lack of suitable courses. Six committees had arranged training for their members, which ranged from attendance at a specific course to "in house" training by the committee's ethicist. Initial training was usually organised when the committee was established but no committee had established a programme of updating members or training new members. Two main approaches to training were identified: training in ethical theory and training in the process of ethical deliberation. Committees with ethicists were more likely to receive education around moral theories and principles, and specific issues such as consent or confidentiality. Several chairmen put forward the view, however, that education aimed at improving critical ethical thinking, and learning to work through issues as a group was at least as important as a detailed knowledge of ethical theories. One chairman said: "An initial introduction for members may be useful, a short two-day course may be helpful in that at least people can reflect on the approach to medical ethical problems. But one should stress again that an effective committee may be one that actually develops its own expertise as it goes along."

4. Clinical ethics committees and clinical governance: The relationship between clinical ethics committees and clinical governance was commented on by many chairmen. Most chairmen of established CECs viewed consideration of the ethical issues as an integral part of providing high quality patient care. They also considered it important, however, for the clinical ethics committee to be seen as separate from the monitoring process of clinical governance. One chairman said: "I think it needs to be seen to be functioning with, but not simply as part of, clinical governance."

5. Potential hindrances to the effective functioning of clinical ethics committees: Al chairmen felt that clinical ethics committees could potentially offer a model for raising ethical standards of patient care in NHS trusts. However, several obstacles were identified that could impede their successful development and their effectiveness. (See table 7.)

\section{Discussion}

Clinical ethics committees (CECs) are developing within UK NHS trusts and their number seems likely to increase rapidly in the next few years. Most established committees have developed as a result of clinicians identifying a need for clinical ethics support, ie there has been a "bottom up" approach. However, with the advent of clinical governance CECs may also develop in a more "top down" manner with the impetus coming from management. Models, other than CECs, of providing ethical support to clinicians have been adopted in some
Table 7 Obstacles to the successful development and effectiveness of a clinical ethics committee

Resources (financial and human)

Availability of training for members

Appropriate expertise on the committee

Reluctance of clinicians (particularly doctors) to recognise and use the committee

Difficulties in raising the profile of the committee

trusts, and are preferred by some health professionals. Results of this study also suggest that many senior clinicians and managers, as well as trust and health authority chief executives, believe that some form of ethics support service is desirable.

The high response rate to the questionnaire surveys ensured a comprehensive coverage of NHS trusts and health authorities. The interviews with the chairmen of all identified CECs also provided comprehensive coverage of this model of clinical ethics support, as well as providing a more in-depth view of the processes and functions of these committees. However, the study had some weaknesses. It was clear from the questionnaire responses that not all senior clinicians and managers were aware of what support was available in their organisation. We may therefore have missed some ethics support services in our questionnaire surveys. This risk was minimised by sending the questionnaire to several people in the same organisation. The perception of a need for a clinical ethics support service in this study is limited to senior professionals only. Other health care workers may not have the same views.

The results of this study raise a number of issues. There are many models, or potential models, for providing clinical ethics support within the UK NHS. Eighty-eight trusts reported some mechanism of providing clinical ethics support other than CECs. It is not possible to say from this study how active or effective these forms of support are, or whether it is just wishful thinking on the part of the respondents that these mechanisms could be used for ethics support. The findings raise the possibility that existing structures in trusts could be developed to provide support and guidance on ethical issues in clinical care as an alternative to a CEC. Health authorities and health boards have a role in providing clinical ethics support to primary care groups and trusts. They too will need to consider appropriate models of providing such support. Although some evaluation of such services has taken place in North America there has been little rigorous evaluation of outcomes, with most research looking at process data such as satisfaction of health professionals and patients. ${ }^{17-19}$ In general satisfaction is high among users of CECs but this accounts for only a small percentage of any professional group within the institution. ${ }^{20}$ Longer term evaluative studies using outcome as well as process data are needed.

Whatever models of clinical ethics support are found to be most suitable, either for individual trusts and health authorities, or more generally within the health service, many of the issues 
i8 Clinical ethics support services in the UK: an investigation of the current provision of ethics support to health professionals in the UK

identified in the interviews with chairmen of CECs will be relevant. There was broad agreement between the chairmen of CECs in many areas. A fundamental point arising from all the interviews was that CECs should be advisory, offering support but not issuing decisions. For the committee to be successful, it must have recognition and support from within the institution at all levels, including administrative and financial support. Many CEC chairmen identified the need for appropriate training or education of committee members as important. The areas identified as important in such education include basic moral theory, ethical analysis, critical thinking, and knowledge of national ethical and legal guidelines. All committee chairmen commented that they were unaware of other CECs and that contact between CECs would be an important method of providing support and education for developing CECs. The sharing of experience and specific guidelines through some form of network would avoid each committee having to "reinvent the wheel".

There was less consensus about the various functions of CECs. Although most committees have concentrated on guidelines and policy formation, some committees see case consultation as the main function of the committee. Most chairmen agree that education of health professionals within the institution and raising awareness of ethical issues is important but there are concerns about how the committee can provide this service. Simila problems were faced by CECs developing in North America. ${ }^{21} 22$

Several of the CECs in the UK are not yet clear about their exact role in the institution and there are concerns about how effective the committees are. Comments from the questionnaire surveys also raise concerns about the effectiveness of a clinical ethics support service, even among those who are very much in favour of raising ethical awareness in clinical practice. It is therefore imperative that any services have clearly stated objectives, and that there is a rigorous evaluation of both process and outcome during their development.

In conclusion, clinical ethics support services, and particularly CECs, are in the early stages of evolution in the UK. There is the opportunity, through good liaison between the existing services, and continuing evaluation, to ensure the development of effective ways of providing such support.

\section{Acknowledgement}

The study reported in this paper was funded by The Nuffield Trust.

Anne Slowther, MRCGP, MA, is NHS RED Primary Care Research Training Fellow at Ethox, Division of Public Health and Primary Care, University of Oxford.
Chris Bunch, MD, FRCP, is Medical Director and Chairman of the Clinical Ethics Committee at the Oxford Radcliffe Hospitals NHS Trust. Brian Woolnough, MA, Bsc, FInstP, is University Lecturer in Science and Education, Department of Educational Studies, University of Oxford. Tony Hope, PhD, FRCPsych, is Professor of Medical Ethics and Director of Ethox.

\section{References}

1 General Medical Council. Seeking patients' consent: the ethical considerations. London: GMC, Feb1999.

2 British Medical Association. Withholding and withdrawing life-prolonging medical treatment. London: BMA, 1999

3 Slowther A, Underwood M. Is there a need for a clinical ethics support service in the UK? fournal of Medical Ethics 1998;24: 207 .

4 Rosner F. Hospital medical ethics committees: a review of their development. Fournal of the American Medical Association 1985; 253:2693-7.

5 Gibson JM, Kushner TK. Will the 'conscience of an institution' become society's servant? The Hastings Center Report 1986;3:9-11.

6 Simon A. Support for ethical dilemmas in individual cases: experiences from the hospital Neu-Mariahilf in Goettingen. fournal of Medical Ethics 2001;27(supp):i18-i20.

7 Van der Kloot H, Meijburg H. Different profiles for the institutional ethics committees in the Netherlands. HEC Forum 1994 ; 6:139-57.

8 Boitte P. The role of the clinical ethicist in the hospital. Medicine, Health Care and Philosophy1 998;1:65-70.

9 McNeill PM, Walters JD, Webster I. Ethics decision-making in Australian hospitals. Medical fournal of Australia 1994;161:487-

10 La Puma J, Stocking CB, Silverstein D, DiMartini A, Siegler $M$. An ethics consultation service in a teaching hospital. fournal of the American Medical Association 1988;260:808-11.

11 Reiter-Theil, S. Ethics consultation on demand: concepts, practical experiences and a case study. fournal of Medical Ethics 2000;26:198-204.

12 Tulsky JA, Fox E. Evaluating ethics consultation: framing the questions. Fournal of Clinical Ethics 1996;7:109-15.

13 Meslin E, Rayner C, Larcher V, Hope T, Savulescu J. Hospital Meslin E, Rayner C, Larcher V, Hope T, Savulescu J. Hospita
ethics committees in the UK. HEC Forum 1996;8:301-15.

14 Watson AR. An ethics of clinical practice committee: should every hospital have one? Proceedings of the Royal College of Physicians of Edinburgh 1999;29:335-7.

15 Wood K, Ellis S. A clinical ethics committee in a small health services trust. Fournal of Medical Ethics 1999;25:420.

16 Slowther A, Hope T, Bunch C, Woolnough B. Clinical ethics support services in the UK: a review of the current position and likely development. www.nuffieldtrust.org

17 La Puma J, Stocking CB, Darling CM, Seigler M. Community hospital ethics consultation: evaluation and comparison with a university hospital service. The American fournal of university hospital ser

18 White J, Dunn PM, Homer L. A practical instrument to evaluate ethics consultations. HEC Forum 1997;9:228-46.

19 McClung JA, Kamer RS, DeLuca M, Barber HJ. Evaluation of a medical ethics consultation service: opinions of patients and health care providers. The American fournal of Medicine 1996;100:456-60.

20 Hoffmann DE. Does legislating hospital ethics committees make a difference? A study of hospital ethics committees in Maryland, the district of Columbia and Virginia. Law, Medicine and Health Care 1991;19:105-19.

21 Blake DC. The hospital ethics committee: health care's moral conscience or white elephant. Hastings Center Report 1992;22:6-

22 Sexson WR, Thigpen J. Organisation and function of a hospital ethics committee. Clinics in Perinatology 1996;23:429-36. 